\title{
LA PRÁCTICA FILOSÓFICA EN LOS PAÍSES NÓRDICOS ${ }^{1}$ PHILOSOPHICAL PRACTICE IN NORWEIAN COUNTRIES
}

\author{
GABRIEL ARNAIZ \\ Universidad de Sevilla \\ gabriel.arnaiz@gmail.com
}

RECIBIDO: 1 DE JUNIO DE 2011

ACEPTADO: 24 DE JUNIO DE 2011

Resumen: En este artículo se expone una visión panorámica de la situación de la práctica filosófica (en un sentido amplio, esto es, incluyendo no sólo el trabajo individual sino también el grupal, aunque centrada más en la OrFi) en los países nórdicos, especialmente en Noruega, así como de sus principales protagonistas, y sus influencias más importantes. Se agrupan los filósofos en tres generaciones: la primera compuesta fundamentalmente por Anders Lindseth, y muy influida por la concepción achenbachiana de la OrFi; la segunda generación, personificada en Henning Herrestad y Helge Svare donde se produce un cierto giro analítico, influidos por el estilo de los filósofos prácticos holandeses,

\footnotetext{
${ }^{1}$ Este artículo, que inicialmente era una presentación al trabajo de dos filósofos noruegos que habían escrito un libro divulgativos sobre la Orientación Filosófica, iba a aparecer de manera simultánea con la traducción del primer capítulo de ese libro en el número 4 de la Revista ETOR, a modo de introducción al trabajo filosófico de estos autores y contextualización de su peculiar enfoque. Por un problema de espacio no apareció entonces en aquel número, así que aproveché para ampliar el campo de análisis de aquel breve artículo y ofrecer una visión más global de lo que estaban haciendo los filósofos prácticos noruegos (un modo de continuar y completar el trabajo iniciado por José Barrientos en su Introducción al Asesoramiento y la Orientación Filosófica, Tenerife, Idea, 2005), con el fin de publicarlo en el siguiente número de la revista, que finalmente no llegó a aparecer. Ahora, después de mucho tiempo casi sin acordándome de lo que escribí hace más de un lustro, ve la luz este añejo artículo en la nueva heredera de aquella revista (que he revisado nuevamente a la luz de los conocimientos que ahora poseo y la distancia de los años — sobre todo para actualizar la bibliografía, añadir algunas nuevas notas y una nueva conclusión-, pero conservando la estructura de entonces). Por ello, no sé si finalmente escribiré - me temo que no-los artículos que adelantaba en diferentes notas a pie de página, pues hoy en día mis intereses intelectuales se encuentran bastante apartados de aquel fervor inicial por la práctica filosófica individual (finalmente he decidido no suprimirlos para indicar al lector que este texto iba a iniciar una serie de artículos exegéticos sobre la Práctica Filosófica —en un sentido amplio, incluyendo no sólo el trabajo individual, sino también el grupal- en diferentes países: Alemania y el enfoque continental (Achenbach y los achenbachianos), el enfoque analítico del «eje atlántico» representado por Norteamérica, Reino Unido y Australia (Marinoff y la APPA, Raabe, P. Grimes, M. Russell, etc.), Holanda (cuyos filósofos han sido capaces de aunar lo mejor de ambos enfoques), Francia (sobre todo el trabajo de Brenifier, pero también de las nuevas prácticas filosóficas) e Italia (Pollastri y el trabajo de los miembros vinculados con la asociación Phrónesis, pero también la labor de Paolo Dordoni con los diálogos socráticos). Por ahora, estos artículos que en aquel momento proyecté (y cuya investigación exhaustiva me ayudó mucho a escribir mi tesina) se quedaron en el tintero de los buenos deseos.
} 
aunque siguen manteniendo un «enfoque blando», y la tercera generación, más ecléctica, personificada por Morten Fastvold, que propone una visión más áspera, influida por Brenifier, y Øyvind Olsholt, que se aleja del enfoque de Lipman para hacer filosofía con niños.

Palabras clave: Práctica Filosófica, Orientación Filosófica, Noruega, Achenbach, Marinoff, Lindseth, Herrestad, Svare, Fastvold

\begin{abstract}
In this article the author presents a global outlook of the situation of Philosophical Practice (considering it not only as Philosophical Counseling, but including also the work with groups, as APPA defends) in the Nordic Contries, specially in Norway, and of their main characters and influences. The philosophers are grouped in three generations: the first, the pioneers, is composed mainly by Anders Lindseth and was very influenced by the achenbachian view of Philosophical Counseling; the second generation, personified by Henning Herrestad and Helge Svare, and in which is produced a certain «analytical turn», influenced by the style of the Dutch philosophical practitioners, although still maintaining a «soft approach»; and the third generation, more eclectic, personified by Morten Fastvold, who proposes a more confrontational approach, influenced by Brenifier, and Øyvind Olsholt, who trascends the Lipman approach of doing philosophy with children.
\end{abstract}

Keywords: Philosophical Practice, Philosophical Counseling, Norway, Achenbach, Marinoff, Lindseth, Herrestad, Svare, Fastvold

\title{
Introducción
}

En el último número de la Revista ETOR presentábamos ante el público hispanohablante la traducción del primer capítulo del libro Filosofía para la vida. Un libro sobre la práctica filosófica ${ }^{2}$, escrito por dos filósofos noruegos relativamente jóvenes, Helge Svare y Henning Herrestad. ${ }^{3}$ Los dos autores son ampliamente conocidos dentro del movimiento internacional de la Orientación Filosófica (OrFi, a partir de ahora), pues son miembros fundadores de la Sociedad Noruega para la Práctica Filosófica, la asociación que organizó en Oslo el VI Congreso Internacional de Práctica Filosófica ${ }^{4}$. Ambos autores pertenecen a la

\footnotetext{
${ }^{2}$ En su versión original: HERRESTAD, Henning y SVARE, Helge, Filosofi for livet. En bok om filosofisk praxis, Unipub, Oslo, 2004.

${ }^{3}$ HERRESTAD, Henning y SVARE, Helge, «En la consulta del filósofo», Revista ETOR, n 4 , Sevilla, 2005, pp. 63-68.

${ }^{4}$ Distinguimos entre Práctica Filosófica, con mayúsculas y en singular, a la denominación de este nuevo campo de investigación filosófica y la emergente disciplina filosófica que está surgiendo, y
} 
denominada por algunos ${ }^{5}$ como «segunda generación» de orientadores filosóficos, los que continuaron con el trabajo pionero de la primera generación (exclusivamente formada por los comienzos en solitario de Anders Lindseth) y crearon la estructura necesaria para que la tercera generación pudiese (compuesta por filósofos como Morten Fastvold) abrir nuevos caminos.

Con el fin de contextualizar el fragmento que en su momento publicamos, nos proponemos describir brevemente las aportaciones que los distintos filósofos práticos noruegos vienen desarrollando desde hace años.

\section{LA PRIMERA GENERACIÓN: ANDERS LINDSETH, EL PATRIARCA}

Lindseth es un filósofo noruego formado bajo los auspicios y tutela de Gerd Achenbach y autor de algunos artículos destacados sobre la materia, que normalmente escribe en alemán. ${ }^{6}$ Los autores del libro que estamos contextualizando han reconocido el magisterio de Lindseth dedicándole una sección específica en su reciente obra. Por ello, la lección inaugural del congreso de Oslo corrió a cargo de Anders Lindseth quien, como veterano del movimiento, repasó las vicisitudes de los cinco congresos

\footnotetext{
práctica/s filosófica/s, con minúsculas y normalmente en plural, para hacer referencia a las diversas metodologías de hacer filosofía y movimientos. Cuando denominamos a estos movimientos en mayúsculas (Orientación Filosófica, Filosofía para Niños, etc.) estamos haciendo referencia más bien a la «disciplina» que estudia esta metodología, al corpus bibliográfico y teórico (al menos, metametodológico) que han ido segregando los miembros del movimiento con los múltiples artículos, monografías y libros en los que reflexionan (es decir, filosofan) sobre su práctica (haciendo metafilosofía, o al menos, metametodología, que sería una rama de la epistemología), mientras que cuando utilizamos las minúsculas (orientación filosófica, diálogo socrático) es para referirnos a la práctica filosófica, a la realidad en que ésta consiste, a la metodología que se utiliza. Más información en ARNAIZ, Gabriel, El giro práctico en filosofía. Análisis y fundamentación de las prácticas filosóficas. Tesina de Investigación. Universidad de Sevilla, 2007 (manuscrito inédito).

${ }_{5}^{5}$ Hemos utilizado como esquema la clasificación en tres generaciones que se esboza en FASTVOLD, Morten, «Beyond method, Anders Lindseth style: The quest to opening up philosophical steps in the consulting room», Philosophical Practice, 1 (3), London, 2005, pp. 171-183 (disponible también en la red en http://www.fastvold-filopraksis.com/artikler_pdf/Lindseth\%20e-print.pdf; última visita el 30 de abril de 2011).

${ }^{6}$ Recientemente los ha reunido en un libro: LINDSETH, Anders, Zur Sache der Philosophischen Praxis. Philosophieren in Gesprächen mit ratsuchenden Menschen, Verlag Kart Aber, Loegstrup, 2005.
} 
anteriores, reconociendo la deuda que el movimiento debe a Achenbach, «no por haber creado la primera consulta filosófica en la práctica, sino por introducir la misma noción de práctica filosófica en el mundo». ${ }^{7}$ Lindseth se considera a sí mismo el «patriarca» de la orientación filosófica en Noruega, «padre espiritual» de la segunda generación de autores, especialmente de sus dos miembros más conspicuos, Herrestad y Svare y, por lo tanto, «abuelo» de los retoños que forman la tercera generación, una hornada que, como veremos, ha salido algo díscola.

\section{Acérrimo achenbachiano}

Lindseth comenzó su práctica en la ciudad de Troms $\emptyset$, al norte del país, en el año 1988, muy influido por la forma de practicar la orientación filosófica de Gerd Achenbach, siguiendo su característico enfoque «más allá del método» (beyond-method) y manteniendo una separación radical entre la OrFi y las terapias. ${ }^{8}$ Junto con la germano-canadiense Petra von Morstein ${ }^{9}$ y con el italiano Neri Pollastri, Lindseth constituye uno de los

\footnotetext{
${ }^{7}$ LINDSETH, Anders, «Philosophical Practice. What is at stake?», en HERRESTAD, Heninng; HOLT, Anders y SVARE, Helge (eds.), Philosophy in Society. Papers presented to the Sixth Internacional Conference on Philosophy in Practice, Unipub, Oslo, 2004, p. 18.

${ }^{8}$ Para hacerse una idea de la concepción de la OrFi de Achenbach, recomendamos el minucioso y extenso artículo de POLLASTRI, Neri, «Gerd Achenbach e la fondazione della pratica filosofica», Maieusis, $\mathrm{n}^{\mathrm{o}}$ 1, Torino, 2001. Esperamos publicar brevemente en esta misma revista un artículo sobre este enfoque con el título de «La práctica filosófica según Achenbach». El problema de la exposición que hace Barrientos su manual es que sólo tiene en cuenta los artículos publicados en inglés, que a mi juicio distorsionan parcialmente el enfoque de Achenbach (pero siempre será mejor eso que nada). Cuando leí los artículos escritos por Pollastri y las traducciones italianas (pues todavía no soy capaz de entender todavía sus textos en alemán) descubrí un Achenbach bastante distinto al que describían sus intérpretes anglosajones (Schuster, Raabe, etc.). Para una comprensión más ajustada de la metodología de Achenbach, habría que consultar sus obras en alemán - hasta el momento son siete- o, en su defecto, leer las traducciones italianas de sus libros (hasta el momento se han traducido tres libros: ACHENBACH, Gerd, La consulenza filosofica, Apogeo, Milano, 2004; ACHENBACH, Gerd, Il libro della quiete interiore. Trovare l'equilibrio in un mondo frenetico, Apogeo, Milano, 2005 y ACHENBACH, Gerd, Saper vivere. Per una vita piena di significato e di valore, Apogeo, Milano, 2006). En español puede consultarse un breve texto de Achenbach, con abundantes notas explicativas y traducciones de varios fragmentos de la traducción italiana de Philosophische Praxis, ACHENBACH, Gerd. «Breve respuesta a la pregunta: “¿Qué es la orientación filosófica"» (traducción y notas de G. Arnaiz), disponible en la red en http://www.asepraf.org/practica\%20filosofica\%20Achenbach.pdf (última visita el 30 de abril de 2011).

${ }^{9}$ Para saber más sobre el modo en que von Morstein practica la OrFi, recomendamos leer dos textos, uno escrito desde la afinidad metodológica y la veneración, y otro más crítico y escéptico. El
} 
más claros exponentes de eso que podríamos denominar como «los achenbachianos $»^{10}$, los discípulos más renombrados $-\mathrm{y}$ también más inflexibles - a la hora de defender este tipo de concepción frente al enfoque anglosajón (compuesto por «los analíticos» ${ }^{11}$ ), al que contemplan como un hijo «bastardo» que ha tergiversado el mensaje del «padre» Achenbach y se ha dejado contaminar por las corrientes psicológicas (especialmente el counseling) y sus prácticas terapéuticas. ${ }^{12}$

\section{La hermenéutica de Ricoeur}

Este profesor de la Universidad de Tromso hace mucho hincapié en el acto de «profunda escucha» que implica la orientación filosófica, aplicando la hermenéutica de Paul Ricoeur en su práctica filosófica. Para Anders, «escuchar al Otro es un desafío hermenéutico (y ético). Y, aún más que escucharlo, entender al Otro es un desafío que podríamos denominar hermenéutico, o fenomenológico, o simplemente filosófico.

primero lo constituye la sección que le dedica en su libro SCHUSTER Shlomit, Philosophy Practice. An Alternative to Counseling and Psychotherapy, Praeger, Westport CT, 1999, pp. 44-47, y el otro es el jugoso artículo de FASTVOLD, Morten «Rooting Philosophy in Lived Experience: some Notes on Petra von Morstein's Lecture and Workshops in Oslo, March 2005», disponible en la red en http://www.fastvold-filopraksis.com/artikler_pdf/MF\%20Essay\%20Petra\%20vM.pdf (última visita el 1 de mayo del 2011), un brillante ejercicio de ironía socrática en el que el autor sutilmente pone al descubierto las deficiencias y limitaciones del enfoque de esta autora canadiense. Nosotros tuvimos la suerte de poder verla en acción en un taller práctico en el penúltimo congreso internacional de diálogo socrático celebrado en Berlín en julio del 2005, y en general compartimos las críticas de Fastvold.

${ }^{10}$ Estamos preparando un artículo sobre «los achenbachianos»: esos acérrimos defensores de la Philosophische Praxis al más puro estilo germano, los sanchopanzescos defensores de la quijotesca fe achenbachiana, los «cuatro fantásticos» de la OrFi, los «cuatro jinetes del Apocalipsis» (¡qué vienen los americanos! ¡sálvese quien pueda!): me estoy refiriendo a von Morstein, Lindseth, Schuster y Pollastri.

${ }^{11} \mathrm{Al}$ igual que en la filosofía universitaria, de la que es fiel reflejo a pesar de todas las proclamas en contra, en la práctica filosófica también existe una división, un conflicto y un cisma entre el «bloque analítico» (la filosofía que se hace en el mundo angloparlante) y el «bloque continental» (la filosofía que se hace en Centroeuropa, bajo la influencia de Alemania, fundamentalmente).

${ }^{12}$ Ampliaré la información que adelanto en este artículo sobre la concepción de la OrFi de los anglosajones (de Marinoff y los miembros de la APPA por un lado — como V. Fery y M. Russell, E. Cohen y la ASCPC - y por otro, de los británicos como Tim LeBon, Nigel Laurie y Cía, así como de sus simpatizantes, los holandeses, Dias, Grassi, Barrientos, Arnaiz, etc.) en mi artículo «Bienvenido Mr. Marinoff», de próxima aparición. [Estas notas cada vez me recuerdan más esas notas orteguianas donde se anunciaban proyectos que nunca llegaron a ser realidad. A pesar de estar tentado de suprimirlas, las dejo porque en el fondo soy un enamorado de este subgénero: la glosa]. 
Considero que este doble desafío de escuchar y entender al Otro es el reto básico para cada orientador filosófico». ${ }^{13}$ Según este filósofo, «la práctica filosófica es aquella situación en la que el visitante (visitor) deposita algo de su vida - y no precisamente algo pequeño - en las manos del orientador filosófico. Esta es la razón por la cual constituye un imperativo ético para el orientador filosófico escuchar el discurso del visitante. Y no solamente un imperativo ético, sino también una exigencia hermenéutica, puesto que si no escuchamos lo que nos ofrece el visitante, tampoco podremos oír lo que tenemos que entender». ${ }^{14}$

\section{Rechazo al enfoque anglosajón de la OrFi}

Los orientadores filosóficos anglosajones, tanto los ingleses - por ejemplo, el grupo de Tim Le Bon que gravita en torno a la $\mathrm{SPP}^{15}$ - como los norteamericanos - la APPA $^{16}$ de Marinoff o la ASPCP $^{17}$ de E. Cohen-, no mantienen una gran diferencia entre el asesoramiento psicológico (Psychological Counseling), o incluso la psicoterapia, y el asesoramiento filosófico, como lo demuestra incluso la misma designación inglesa de la disciplina (Philosophical Counseling) y defienden una concepción de la OrFi más bien «híbrida» o «contaminada» ${ }^{18}$.

\footnotetext{
${ }^{13}$ LINDSETH, Anders, «What The Other Says And What (S)He Talks About: Some Foundations of a Theory of Philosophical Practice», en CURNOW, Trevor (ed.), Thinking through Dialogue, Practical Philosophy Press, Oxford, 2001, p. 135.

${ }^{14}$ LINDSETH, Anders, op. cit., p. 136.

${ }^{15}$ La SPP es la Society for Philosophy in Practice, esto es, la Sociedad por la Práctica de la Filosofía, que edita la revista Practical Philosophy. Más información en su web, en http://www.practicalphilosophy.org.uk.

${ }^{16} \mathrm{La}$ APPA es la American Philosophical Practitioners Association, es decir, la Asociación Americana de Filósofos Prácticos, que edita la revistaPhilosophical Practice: Journal of the APPA. Más información en su web: en http://www.appa.edu.

${ }^{17}$ La ASPCP es la American Society for Philosophy, Counseling and Psychotherapy, esto es, la Sociedad Americana para la Filosofía, el Asesoramiento y la Psicoterapia, que edita el International Journal of Philosophical Practice (Revista Internacional de ráctica Filosófica). Más información en su web: http://aspcp.org .

${ }^{18}$ Para conocer la argumentación de aquellos filósofos que defienden que la orientación filosófica no se distingue de otras formas de orientación y que constituye en esencia una «terapia para cuerdos», puede consultarse el artículo de RUSSELL, Michael, «Philosophical Counseling is not a distinct field: Reflections of a Philosophical practitioner», International Journal of Philosophical Practice, Vol. 1, $\mathrm{n}^{\mathrm{o}}$ 1, 2001 (disponible en http://www.aspcp.org/ijpp/russell.pdf; último acceso 30 abril 2011), o el de HOFFMAN, Eric, «The future of "Philosophical Counseling": a modest vision», International
} 
Sin lugar a dudas, Lou Marinoff es el filósofo práctico ${ }^{19}$ más controvertido y polémico, dentro y fuera del movimiento, no sólo por sus libros divulgativos —Más Platón y menos Prozac (1999) y Pregúntale a Platón $(2003)^{20}$ - sino también por algunas de sus iniciativas (fundación de la APPA, separándose de la ASPCP, formación a filósofos prácticos en muy poco tiempo, admisión del I Ching en consulta, etc.). Sin embargo, debemos reconocerle también ciertas virtudes: ha sido la persona que ha globalizado el fenómeno (organizando el primer congreso internacional), difundiendo al gran público y a los potenciales especialistas la «buena nueva» (a través de sus libros y apariciones públicas), quien ha comprendido la envergadura de la Práctica Filosófica $\left(\mathrm{PF}^{21}\right)$ y toda su potencialidad —no limitándose únicamente a la Orientación Filosófica (Philosophical Counseling), sino incorporando también otros movimientos que han surgido paralelamente ${ }^{22}$, como los cafés filosóficos, la Filosofía para Niños $(\mathrm{FpN})$ y los Diálogos Socráticos

Journal of Philosophical Practice, Vol. 1, $\mathrm{n}^{\mathrm{o}}$ 4, 2003 (disponible en línea en http://www.aspcp.org/ijpp/Hoffman.pdf; último acceso 30 abril 2011), así como el libro de MARINOFF, Lou, Philosophical Practice, New York, Academic Press, 2001, pp. 81-7 y 271-4.

${ }^{19}$ Los filósofos angloparlantes utilizan el término de philosophical practitioner para referirse a aquellos filósofos que hacen algún tipo de práctica filosófica, tanto individual (orientación filosófica) como grupal (cafés filosóficos, diálogos socráticos, talleres de filosofía, etc.) y que literalmente podría traducirse como práctico filosófico o practicante filosófico, neologismos que han tenido menos fortuna que el de filósofo práctico, que es el que nosotros utilizamos, a pesar de que podría confundirse con el filósofo que teoriza sobre problemas filosóficos de tipo práctico, es decir, que hace filosofía práctica (tradicionalmente ética, política y economía), y que en inglés se denomina como practical philosopher o ethicicist, o con el filósofo que teoriza sobre problemas filosóficos prácticos contemporáneos (el aborto, la eutanasia, el medio ambiente, las guerras, etc.), y que los angloamericanos denominan como applied philosopher.

${ }^{20}$ Desde que escribí este artículo Marinoff ha publicado otro libro divulgativo, El Abc de la felicidad, Barcelona, Ediciones B, 2006), que se aparta del análisis de casos de los libros anteriores y aborda cuestiones teóricas de mayor calado, como la guerra de los sexos, el declive de la educación universitaria, el conflicto palestino-israelí, etc.

${ }^{21}$ Utilizaremos las mayúsculas (y a veces simplemente las iniciales: PF) para hacer referencia al movimiento internacional que se ha institucionalizado y al reciente campo de investigación que se está roturando (esto es, a la naciente disciplina filosófica), y las minúsculas para referirnos al conjunto de las prácticas filosóficas desde un punto de vista fáctico y real (como metodologías a aplicar, como una realidad existente de la se parte, como los diálogos filosóficos que mantienen dos o más personas, etc.).

${ }^{22}$ Para más información sobre los distintos movimientos que forman la Práctica Filosófica, su génesis y evolución, y cómo se han ido institucionalizando, remito a ARNAIZ, Gabriel, «El giro práctico de la filosofía», Diálogo filosófico, Madrid, $\mathrm{n}^{\circ}$ 68, 2007 (disponible también en la red en http://www.ciudadredonda.org/admin/upload/files/1cr_t_adjuntos_268.pdf; última visita el 1 de mayo del 2011). 
(DS)_- y quien ha incluido en su concepción de la PF, además de la OrFi, la práctica filosófica con grupos (Group Facilitation) y el trabajo con empresas e instituciones (Philosophical Consulting) ${ }^{23}$. En el libro que ha escrito dirigido a los especialistas ${ }^{24}$, explica detalladamente $-\mathrm{y}$ con una magnífica prosa - cada una de los tres ámbitos de los que se compone la PF.

\section{La OrFi como alternativa a las psicoterapias}

La postura achenbachiana a este respecto es clara y rotunda: la orientación filosófica aparece históricamente como una «alternativa a la psicoterapia», no como una «psicoterapia alternativa», de ahí que se aleje del paradigma terapéutico tradicional de enfermedad-diagnosistratamiento-cura. Por este motivo, la concepción achenbachiana de la orientación filosófica, compuesta fundamentalmente por filósofos de «tradición continental» (entre los que se encuentran la mayoría de lo alemanes, austriacos y suizos, los daneses como Finn Th. Hansen, los noruegos como Anders Lindseth, los italianos de Phronesis como Pollastri, o los israelíes como Schuster) consideran que en rigor no debería confundirse esta vertiente de «terapia de inclinación filosófica» con la práctica cualitativamente diferente en que consiste la Philosophische Praxis, originada históricamente como oposición y complemento, por un lado, con la filosofía universitaria ${ }^{25}$ exclusivamente

\footnotetext{
${ }^{23}$ Para saber sobre este enfoque amplio de la PF que preside este artículo, véase ARNAIZ, Gabriel, «QQué es la Filosofía Práctica?», A parte rei, $\mathrm{n}^{\circ}$ 53, 2007, disponible en línea en http://serbal.pntic.mec.es/AParteRei/arnaiz53.pdf (última visita el 9 de mayo del 2011). Debo decir que entonces seguía hablando de Filosofía Práctica para designar a lo que hoy refiero con Práctica Filosófica, y, siguiendo la tradición filosófica, reservo el término de Filosofía Práctica para designar a la ética, la política y la economía.

${ }^{24}$ MARINOFF, Lou, Philosophical Practice, New York, Academic Press, 2001.

${ }^{25}$ Preferimos utilizar la expresión «filosofía universitaria» para referirnos a la teoría filosófica que se hace en las universidades a la más común «filosofía académica» (que suele ser un calco del inglés, academic philosophy, la filosofía que se hace en la «academia». Sin embargo, los hispanohablantes no solemos utilizar el término academia para referirnos al profesorado universitario; academia para nosotros significa normalmente la real academia de la lengua, o de la historia. Es posible que exista teoría filosófica (y de alto nivel) fuera de la Universidad (así lo demuestra la historia de la filosofía, pues la mayoría de los filósofos modernos antes de Kant - Montaigne, Bacon, Descartes, Hobbes, Spinoza, Locke, Hume, Leibniz...- forjaron sus teorías filosóficas fuera de los claustros universitarios), por eso no me parece adecuado equiparar «filosofía académica» con «filosofía universitaria» (pues la «filosofía administrada o institucionalizada», al menos en nuestro país -y
} 
teórica y, por otro, con el enfoque terapéutico de tratamiento de los problemas existenciales del individuo. Podemos encontrar una excelente descripción de este enfoque «puro» de la orientación filosófica, sin adherencias terapéuticas ni psicológicas, en el libro Il pensiero e la vita, de Neri Pollastri ${ }^{26}$.

Sin embargo, los orientadores filosóficos de la tercera generación ${ }^{27}$ tienden más bien a difuminar las supuestamente marcadas diferencias

también en Francia e Italia-, incluye no sólo la filosofía universitaria, sino también la filosofía «secundaria», es decir, la teoría filosófica que imparten los filósofos a sus alumnos de secundaria y bachillerato, así como la teoría filosófica que estos desarrollan), y mucho menos «teoría» con «universidad» (Considero muy atinados los análisis de Gustavo Bueno al respecto, distinguiendo la «filosofía universitaria» de la «filosofía académica», y la dialéctica entre «filosofía institucionalizada» y «filosofía mundana». Ver BUENO MARTÍNEZ, Gustavo, El papel de la filosofía en el conjunto del saber, Ciencia Nueva, Madrid, 1970, pp. 244-279. Aunque nadie ha sido tan cáustico como Schopenhauer en Sobre la filosofía universitaria (Tecnos, Madrid, 1991). Véase también el resumen de este opúsculo y el cotejo con la filosofía de G. Bueno en GIMÉNEZ PÉREZ, Felipe, «Sobre la filosofía universitaria», El Catoblepas, n. ${ }^{\circ}$ 60, 2007.

${ }^{26}$ A pesar de que pertenece a una generación posterior a Von Morsein y Lindseth, Neri Pollastri sigue defendiendo con la rotundidad típica de los nuevos conversos un enfoque puramente achenbachiano de la OrFi en el que probablemente sea uno de los libros más completos que hasta el momento se han escrito sobre la PF: POLLASTRI, Neri, Il pensiero e la vita. Guida alla consulenza e alle pratiche filosofiche, Milano, Apogeo, 2004.

27 Podemos considerar a los autores - fundamentalmente «continentales»- que comenzaron a practicar la práctica filosófica en la los ochenta (primera década: 80-90), como pertenecientes a la «primera generación» de filósofos prácticos (y que tienen ahora entre sesenta y ochenta años), y entre los que Achenbach sería su protagonista más destacado. La «segunda generación» estaría formada por filósofos más jóvenes (entre sesenta y cuarenta años) que entraron en el movimiento en la siguiente década (1990-2000), sobre todo norteamericanos, y Lou Marinoff sería su más conspicuo representante. La «tercera generación» estaría formada por aquellos filósofos (entre los cuarenta y los veintitantos años) que descubrieron el movimiento alrededor del año 2000 (y ocuparía la década siguiente: 2000-2010), y entre los que me encuentro. Probablemente sería mejor hablar utilizar un criterio más bien objetivo (décadas) que subjetivo (generaciones), y hablar mejor de «oleadas» (primera oleada entre los 1980 y los 1990, segunda oleada en los años 1990-2000 y tercera oleada en 2000-210) que de generaciones, como hacen algunos intérpretes del materialismo filosófico. Pues algunos filósofos prácticos, como por ejemplo Fastvold, que estrictamente hablando pertenecen a la segunda generación, se incorporan al movimiento en la «tercera oleada», de ahí que nosotros los ubiquemos en la tercera generación. A pesar de ello, seguimos manteniendo la nomenclatura de generaciones, pues en términos generales (y salvo algunas excepciones) sí que se cumplen estas características. CALDERÓN GORDO, Sharon, «El Congreso de Murcia y las oleadas del materialismo filosófico», El Catoblepas, n. ${ }^{\circ}$ 20, 2003, disponible en línea en http://www.nodulo.org/ec/2003/n020p20.htm (última visita el 15 de mayo del 2011): «Según esto, en el curso del desarrollo de una corriente filosófica (como pueda serlo la filosofía analítica o el materialismo filosófico) habrá que distinguir no ya generaciones sino olas u oleadas según las personas que se incorporan al desarrollo de esa corriente o sistema filosófico, cualquiera que sea, en principio, la generación a la que pertenezcan, aunque hay grandes probabilidades de que los más jóvenes biológicamente formen parte también de las oleadas posteriores. Pero no habrá por qué 
entre estos dos grandes concepciones (la «continental», representada por Achenbach y sus acólitos, y la «analítica» de los angloamericanos como Marinoff, LeBon y compañía), optando por un enfoque «ecléctico» ${ }^{28}$ que recoja lo mejor de ambas tradiciones ${ }^{29}$.

\section{LA SEGUNDA GENERACIÓN: HERRESTAD Y SVARE}

Herrestad fundó en 1998 la asociación noruega (en noruego, la Nork Selskap for Filosofisk Praksis ${ }^{30}$ ) con un pequeño grupo de jóvenes filósofos noruegos interesados por la orientación filosófica, asociacion que, desde sus orígenes, se ha caracterízado por seguir el enfoque práctico y cooperativo iniciado por los holandeses a finales de los ochenta e inicios de los noventa.

\section{Inspiración holandesa}

El modelo holandés de formación de los orientadores filosóficos se basa en la simulación de situaciones reales de orientación donde los aprendices de orientadores filosóficos se turnan para adoptar los papeles de consultante y de orientador, proponiendo auténticos problemas reales de la vida personal de los participantes. El resto de los asistentes es testigo de la consulta con el fin de analizar posteriormente la situación producida y las estrategias utilizadas por ambos participantes. Las

\footnotetext{
explicar que una persona de mayor edad se incorpore al sistema en oleadas más recientes, como tendría que hacerlo la teoría de las generaciones. Asimismo quienes pertenecen a una oleada en un momento dado, pueden desvincularse del sistema en otro momento de su evolución personal, y quienes pertenecían a otra corriente pueden incorporarse al sistema (por ejemplo, al materialismo filosófico) en otro momento de su evolución biográfica» (p. 20).

${ }^{28}$ Como ejemplos de esta «nueva generación» ecléctica, citaremos el trabajo que viene desarrollando Morten Fastvold en Noruega, Paola Grassi en Italia, José Barrientos o Gabriel Arnaiz en España, y Jorge Dias en Portugal.

29 Para más información sobre la polémica entre «analíticos» y «continentales», puede también consultarse el artículo de VOLPONE, Alessandro, «L'orizzonte variegato della consulenza filosofica: una discusione generale della pratica», Phronesis, año I, número 0, Roma, pp. 29-43.

${ }^{30}$ En la web de la asociación (www.nsfp.no) se nos informa, entre otras cosas, de que actualmente la asociación tiene alrededor de veinte miembros afiliados. Podemos ver las fotos de los más destacados y visitar sus páginas personales, como por ejemplo, la de Herrestad (www.perspectiv.as), la de Svare (www.svare.no) y la de Anders Holt (www.sophia.no).
} 
sesiones a veces se graban en vídeo para poder examinar así con mayor detenimiento hasta los menores detalles. Uno de los objetivos más importantes de este enfoque consiste en aprender a no imponer nuestras ideas y visión del mundo (si actuamos como orientador) a nuestro consultante. Según Dries Boele, «uno aprende mucho cuando representa el papel de consultante, puede que incluso más que cuando actúa como orientador ${ }^{31}$. Según nos cuenta este filósofo, durante los dos años que duró el proceso de formación, participó, junto con otros cuatro compañeros más, en unas cincuenta sesiones de entrenamiento.

\section{El modelo de Oslo}

Los noruegos, coordinados por Herrestad, aplicaron a su vez este enfoque a su contexto, desarrollando el «modelo de Oslo», que fue descrito con mucha originalidad por Henning en el V Congreso Internacional sobre Práctica Filosófica celebrado en Oxford ${ }^{32}$. En este artículo Henning simula un diálogo con una hipotética compañera, y le cuenta el proceso de formación de dos años en el que él y otros compañeros filósofos entre ellos Helge Svare- se embarcaron hasta que se sintieron suficientemente preparados como para poder ejercer su labor como orientadores filosóficos con sus futuros consultantes de manera eficiente. (Nada que ver, por otra parte, con otros modelos de formación que conocemos, en los que hay mucha teoría, pero muy poca práctica real.)

\section{El VI Congreso Internacional (Oslo, 2001)}

Nuestros autores, pues, forman parte de lo más granado de esa segunda generación de jóvenes orientadores filosóficos de los países nórdicos, pues no sólo Noruega está fuertemente implicada en el movimiento, sino

\footnotetext{
${ }^{31}$ BOELE, Dries, «The training of a Philosophical Counsellor», en LAHAV, Ran y TILLMANS, María (eds.), Essays on Philosophical Counselling, University Press of America, Banham, 1995, p. 37. Este artículo, junto el de otra filósofa holandesa contenido en el mismo volumen (JONGSMA, Ida, «Philosophical Counseling in Holland: History and Open Issues», op. cit, p. 25-34), son de imprescindible consulta para conocer el modelo holandés de formación de orientadores filosóficos.

32 HERRESTAD, Henning, «The Oslo Model: a successful Two Year Training Programme in Philosophical Counselling», en CURNOW, Trevor (ed.), Thinking through Dialogue, Practical Philosophy Press, Oxford, 2001, pp. 11-15.
} 
también Dinamarca ${ }^{33}$ (entre los que destacan Finn Th. Hansen ${ }^{34}$ ), Suecia y Finlandia ${ }^{35}$. Recordemos a nuestros lectores que, antes de publicar Filosofi for livet, un libro para el público en general en el que describen las influencias teóricas de su práctica (Achenbach, Lindseth, Ricoeur) y relatan algunos casos prácticos (como el descrito en el capítulo que ofrecimos en un número anterior de la revista), Svare y Henning ya habían editado con anterioridad una obra de bastante envergadura, aunque dedicada a un público más especializado, Philosophy in Society ${ }^{36}$, libro que recopila la mayoría de los artículos y comunicaciones presentados en el VI Congreso Internacional de Práctica Filosófica. Con la publicación de esta obra, quedó demostrada de forma fehaciente en el ámbito internacional el vigor y la solidez de la «comunidad nórdica» de filósofos prácticos, fuertemente vinculada con la «comunidad germana» (más «rígida» en sus postulados, y personificada por Achenbach, von Morstein y Lindseth) y la «comunidad holandesa» (más flexible y pragmática en sus postulados y muy cercana a la sensibilidad anglosajona: Jos Kessels, Dries Boele, Ida Jongsma, Ag Hoogendijk, Eric

\footnotetext{
${ }^{33}$ Recordemos que no por casualidad, el VII Congreso Internacional de Práctica Filosófica (cuyo título fue «Philosophical Practice. A question of Bildung?») se celebró en Copenhague en julio del 2004, con una nutrida presencia de filósofos nórdicos y organizada por el propio Finn y sus colaboradores de la Universidad de Educación de Copenhague.

${ }^{34}$ Finn Thorbjørn Hansen es presidente de la SDFP, la Sociedad Danesa para la Práctica Filosófica, autor de varios libros en danés sobre el tema (HANSEN, Finn T., Sokratisk dialoggruppe, Gyldendal, Copenhague, 2000 y HANSEN, Finn T., Det filosofiske liv. Et dannelsesideal for eksistenspaedagogikken, Hans R. Forlag, Copenhague, 2002) y de algunos artículos en inglés sobre la aplicación de la práctica filosófica al campo de la educación, como HANSEN, Finn T., «Eros, Authenticity and Bildung as Key-words for Philosophical Practice in Teacher Training», en Compendium for Paper Presentation of the 7th Internacional Conference on Philosophical Practice, Denmark, 2004, pp. 68-85 y HANSEN, Finn T., «The Use of Philosophical Practice in Lifelong and Self-Directed Learning», en HERRESTAD, Heninng; HOLT, Anders y SVARE, Helge (eds.), Philosophy in Society, Unipub, Oslo, 2004, p. 61-73.

${ }^{35}$ De Finlandia debemos destacar la labor de Antti Mattila, presidente de la Sociedad Finlandesa para la Práctica Filosófica fundada en 1999 y autor de algunos artículos interesantes, como MATTILA, Antti, «Cultivating the flexible mind: Epictetus and the Reframing», en CURNOW, Trevor (ed.), Thinking through Dialogue, Practical Philosophy Press, Oxford, 2001, pp. 73-75, o «On Catharsis and Anger», en HERRESTAD, Heninng; HOLT, Anders y SVARE, Helge (eds.), Philosophy in Society, Unipub, Oslo, 2004, pp. 165-170.

${ }^{36}$ HERRESTAD, Heninng; HOLT, Anders y SVARE, Helge (eds), Philosophy in Society. Papers presented to the Sixth Internacional Conference on Philosophy in Practice, Unipub, Oslo, 2004.
} 
Boers, Hans Bolten ${ }^{37}$, etc.), pues de los veintiséis artículos publicados en el libro, la mitad pertenecen a filósofos de estos tres países.

\section{Se publica Philosophy in Society}

Peter B. Raabe, uno de los autores más respetados dentro del movimiento $\mathrm{y}$ autor de varios libros sobre esta nueva disciplina, escribía sobre Philosophy in Society este elogioso comentario: «recomiendo encarecidamente este libro a estudiantes, filósofos prácticos y cualquier persona interesada en la práctica de la filosofía, pues, según mi opinión, constituye la colección de comunicaciones más legible y cuidadosamente seleccionada de todas las que hasta la fecha han sido publicadas $»^{38}$. Este autor considera que con la publicación de estas actas se ha llegado por fin a una cierta madurez de la disciplina, superando definitivamente los estadios «balbucientes» de décadas anteriores en los que los filósofos que se embarcaban en este proyecto constantemente debían estar justificando su práctica. Según nos confiesa el filósofo canadiense: «Me costó cierto tiempo darme cuenta qué era exactamente eso que tanto me gustaba del libro y que me produjo tanta satisfacción al leerlo, en comparación con las actas de anteriores congresos. Finalmente, caí en la cuenta: la mayor madurez del conjunto. No sólo nos encontramos ante una articulación más convincente de la práctica filosófica, sino que se percibe una aceptación de que ésta es de hecho una práctica legítima que ya no necesita ser defendida por sus practicantes. ¡Por fin, qué descanso! Eso me demuestra que existe una mayor apreciación de la práctica filosófica, proveniente quizás de una experiencia más amplia y profunda por parte los asistentes al congreso. Me pregunto si esto se debe al hecho de que puede haber habido un porcentaje mayor de personas con una práctica

\footnotetext{
${ }^{37}$ La comunidad holandesa de filósofos prácticos es una de las más dinámicas e innovadoras, y sus aportaciones son de imprescindible conocimiento, especialmente en el trabajo con grupos y en el ámbito de las organizaciones. A ver si me animo a escribir ese artículo sobre la PF en Holanda y de su enfoque ecléctico (uno de los países que más me han influido en mi propia práctica filosófica, y en mi concepción de la PF). Hablé de los holandeses, sobre todo de su trabajo en el ámbito de las organizaciones, en artículo de ARNAIZ, Gabriel, «Una aproximación a la Práctica Filosófica en las Organizaciones:», Búho. Revista electrónica de la AFFI, $\mathrm{n}^{\circ}$ 5, Sevilla, disponible en la red en http://elbuho.aafi.es/buho5/gabriel.pdf (última visita el 30 de abril de 2010).

${ }^{38}$ RAABE, Peter, «Review of Philosophy in Society», Practical Philosophy, vol. 6, n 1 , London, año 2003, p. 121.
} 
real y efectiva entre los participantes que en congresos anteriores. Sea cual fuere la razón, este libro es un producto verdaderamente sólido.» ${ }^{39}$

\section{Un diálogo socrático reducido}

En Philosophy in Society podemos leer el artículo de Herrestad ${ }^{40}$ en el que se nos propone un modelo de diálogo neosocrático (en la tradición de Leonard Nelson y Gustav Heckman) de corta duración («que puede desarrollarse en tres o cuatro horas, e incluso en una, si fuese preciso«), que ellos han bautizado como «Short Socratic Dialogue» (algo así como mini-diálogo socrático), con algunas modificaciones importantes con respecto a la metodología alemana y más cercano —nuevamente- al enfoque flexible y pragmático de los holandeses, quienes en su momento adaptaron esta técnica para que pudiese funcionar en otros entornos además de en el ámbito educativo, es decir, para el ámbito empresarial y el entorno de las organizaciones. Henning y Helge nos dicen que «han observado que el núcleo esencial del diálogo socrático está formado por un grupo de personas que investigan una cuestión determinada mediante el análisis pormenorizado de una historia contada por uno de los miembros del grupo para iluminar su entendimiento de dicha cuestión» ${ }^{41}$.

Por lo tanto, nos proponen un diálogo socrático dividido únicamente en tres pasos fundamentales: primero, se elegirá el concepto a investigar; segundo, se elegirá la «historia» (el ejemplo personal obtenido de la vida concreta de cada uno) que pueda iluminar el concepto, y por último, se investigará cómo dicha «historia» puede iluminar aquel concepto. Es muy importante que el concepto a tratar se formule de forma positiva: por ejemplo, si estamos intentando tratar al cuestión de algunas prácticas laborales que implican la discriminación racial, intentaremos centrar la atención en el análisis del concepto de «no discriminación», de «respeto», de «igualdad en el trato», etc. Otra característica peculiar del enfoque noruego —que a mí me gusta utilizar ${ }^{42}$ - es el hecho de que los

\footnotetext{
${ }^{39}$ Ibíd., p. 120.

${ }^{40}$ HERRESTAD, Henning, «Short Socratic Dialogue», en HERRESTAD, Heninng; HOLT, Anders y SVARE, Helge (eds.), Philosophy in Society. Papers presented to the Sixth Internacional Conference on Philosophy in Practice, Unipub, Oslo, 2004, pp. 91-102.

${ }^{41}$ Ibíd., p. 92

${ }^{42}$ La primera vez lo hice en las IV Jornadas de Medicina y Filosofía que organizó la facultad de
} 
participantes —o en su defecto, el facilitador ${ }^{43}$ - otorguen un «título» sugerente a la historia que van a contar.

\section{La filosofía del diálogo}

Helge Svare, por su parte, escribe un artículo en ese mismo libro donde nos plantea la necesidad de que los orientadores filosóficos desarrollen una «filosofía del diálogo», puesto que todo su trabajo práctico se basa en él. ${ }^{44}$ La reflexión surge por una pregunta que le hace un periodista televisivo acerca de cuál era la teoría desde la que él desarrollaba su práctica. Svare hace suya la pregunta, planteándose la necesidad de reflexionar sobre la práctica filosófica (práctica, que por otra parte, no lo olvidemos, propugna, según «enfoque feyerabeniano» de Gerd Achenbach, una ausencia de metodología previa y predefinida a aplicar, diferenciándose así de otros tratamientos terapéuticos —el psicoanalítico, por ejemplo- y del modelo clínico usualmente aplicado en ellos, modelo del que se nutren la mayoría de los filósofos noruegos) desde la propia práctica y de elaborar algunos principios claros que sean el punto de partida para un posterior desarrollo teórico que pueda legitimar teóricamente una práctica profesional emergente. Reconoce las aportaciones de Aristóteles y de la teoría narrativa en este campo (especialmente McIntyre, Turner y Ricoeur), admitiendo que «en cierto sentido, las historias que nos contamos a nosotros mismo definen tanto quienes somos como el tipo de vidas que vivimos» ${ }^{45}$. Comenta también que el rasgo más sobresaliente de la orientación filosófica (muy en consonancia con la línea achenbachiana de considerar al «invitado» guest - como una especie de «amigo») es una indeterminada y casi inefable sensación de felicidad o de bienestar que uno siente - tanto el

\footnotetext{
filosofía de la Universidad de Sevilla en el 2005, y en las que facilité un diálogo socrático sobre el sufrimiento con un grupo de unas ocho personas.

${ }^{43}$ Con respecto al término que designa la persona que dirige un diálogo socrático, los anglosajones y holandeses — siguiendo en esto a los alemanes - han optado claramente por la opción de facilitador (facilitador), mientras que los escasos franceses que la practican suelen utilizar el término de animateur (animador), que es el término que los francófonos suelen usar para referirse al filósofo que dirige un café filosófico o un taller de filosofía.

${ }^{44}$ SVARE, Helge, «The Philosophy of Dialogue», en HERRESTAD, Heninng; HOLT, Anders y SVARE, Helge (eds.), Philosophy in Society, Unipub, Oslo, 2004, pp. 243-250.

${ }^{45}$ Ibíd., p. 248.
} 
orientador como el consultante- después de haberse involucrado en un diálogo filosófico, quizás por el hecho de haber sido escuchado sin ser juzgado. Y nos dice: «¿Cómo describiría esta felicidad? Entre otras cosas que podría decir, se encuentra ésta: es una felicidad similar a la que uno siente cuando se reencuentra con un buen amigo, e incluye un cierto elemento de seguridad y una sensación de ser aceptado» ${ }^{46}$.

Aunque en un principio podría pensarse que la labor que desarrolla un orientador filosófico en la consulta consiste «simplemente en hablar» con sus consultantes, puesto que - en consonancia con la concepción achenbachiana - no posee una teoría que dé explicación de su práctica y le respalde teóricamente, Svare nos aclara este punto con la siguiente reflexión: «Me digo a mí mismo que lo que hago cuando le pido a la gente que hablen de sí mismos, de sus vidas, y cuando intento que sean conscientes de los conceptos que suelen utilizar para estructurar sus vidas: todo esto que hago no es "simplemente hablar", sino que constituye un poderoso instrumento que les permite reflexionar sobre el modo en la que se definen a sí mismos, y puede que también permita que redefinan aspectos de su autoconocimiento. Además, el espacio que les ofrezco para esta redefinición no se puede encontrar dentro del entorno social ordinario. Incluso si eres lo suficientemente afortunado como para encontrar un miembro de tu familia, un amante o un amigo con quien entablar buenos diálogos, puede que sólo muy pocas veces puedas reflexionar libremente sobre tu propia vida -y todos sus aspectos-, como cuando penetras en el espacio de encuentro del orientador filosófico. Con demasiada frecuencia, las personas con las que solemos hablar tienen otras prioridades antes que la de permitirte reflexionar libremente, o puede que el diálogo esté contaminado por sentimientos negativos que enturbien ese mismo proceso. Finalmente, me gusta pensar que al crear este tipo de espacio, al dejar que las personas me cuenten la historia de sus vidas, no sólo estoy permitiendo que se definan a sí mismos y redefinan las vidas que están viviendo, sino que estoy permitiendo también que entren en un campo de actividad en el que la naturaleza humana puede desarrollarse plenamente, en consonancia con el modelo aristotélico comentado anteriormente. Me gusta pensar que

\footnotetext{
${ }^{46}$ Ibíd., p. 246.
} 
embarcarse en un diálogo filosófico es algo parecido a tocar un instrumento, estar con los amigos, pasear por el bosque, y otras actividades parecidas. Todas ellas tienen en común con la primera el hecho de que no poseen únicamente un valor instrumental, sino que tienen valor por sí mismas, como actividades a través de las cuáles se desarrollan aspectos esenciales de nuestra humanidad» ${ }^{47}$.

\section{El VII Congreso Internacional (Copenhague, 2004)}

En el VII Congreso Internacional de Práctica Filosófica que se celebró en Copenhague, algunos miembros del Grupo ETOR (J. Barrientos, J. Baroni y G. Arnaiz) tuvimos la oportunidad de encontrarnos con los autores de Filosofía para la vida y hacerles una entrevista. Allí nos contaron cómo empezaron en esto de la práctica filosófica (varios años como voluntarios en el teléfono de la esperanza), nos explicaron con más detalle el modelo noruego de formación que habían desarrollado con tanto éxito, las características que debe poseer un buen orientador, la estructura del libro, etc. ${ }^{48}$ También pudimos ser testigos de una muestra del modo noruego de orientación filosófica (eso que Morten Fastvold denomina «estilo cuidadoso») que practicó Henning con una chica voluntaria y en el que trataron el tema de «ipor qué me produce rechazo el hecho de tener que dar una propina?». La particularidad de la sesión residió en que Henning permitió que cada cierto tiempo se instaurase un metadiálogo en el que los asistentes pudiesen realizar comentarios sobre las estrategias utilizadas por el filósofo noruego.

\section{Prevenir el suicidio con la filosofía}

En este último congreso, Herrestad, que ahora trabaja — además de cómo orientador filosófico- como profesor ayudante de la Facultad de Medicina de Oslo, dentro del equipo de investigación del Instituto de

\footnotetext{
${ }^{47}$ Ibíd., pp. 249-250.

${ }^{48}$ Fue también allí donde comenzaron las primeras conversaciones para una posible traducción del libro de estos autores. Al final, el proyecto se estancó. Quizás algún día encuentre las ganas suficientes de transcribir (y comentar) las entrevistas que entonces hice a Svare y Herrestad, a Achenbach, a Ida Jongsma o a Michael Russell.
} 
Prevención del Suicidio, presentó una comunicación en la que desarrolla un procedimiento en cinco pasos para prevenir el suicidio. ${ }^{49}$ En primer lugar, hay que buscar signos de que la persona en cuestión es un suicida; en segundo lugar, debemos comprobar si el consultante piensa en el suicidio; en tercer lugar, hay que comprobar el riesgo de suicidio inminente; en cuarto lugar, debemos explorar la ambigüedad del consultante sobre el hecho de vivir y de morir, y por último, hay que llegar con el consultante a un acuerdo para buscar ayuda en caso de existir un deseo efectivo de suicidio.

\section{Aplicación de Kant a la OrFi}

Por su parte, Svare presentó una comunicación sobre «La teoría kantiana sobre la Bildung ${ }^{50}$ y su relevancia para la práctica filosófica», en la que analiza la aplicabilidad de ciertos elementos kantianos a la práctica filosófica. En concreto, de la ética kantiana, la necesidad de establecer principios generalmente válidos como una propuesta alternativa para un matrimonio en crisis que solía resolver sus conflictos siguiendo un «modelo de negociación» ad hoc, esto es, el uso de algunos principios de aplicación general para cualquier conflicto, en lugar de acudir continuamente a componendas contextuales y casuísticas.

Partiendo de la observación de Kant de que nuestras prácticas vitales suelen ser inconscientes o semiconscientes y de que posteriormente se reflexiona sobre esas mismas prácticas, dando lugar al descubrimiento de las reglas que las gobiernan (por ejemplo, primero hablamos una lengua y posteriormente reflexionamos sobre las reglas gramaticales implícitas), Svare concluye el principio de que «a través de la abstracción de nuestras prácticas podemos explicitar las reglas que subyacen a las mismas, lo que nos permite reflexionar sobre dichas prácticas de forma muy útil» ${ }^{51}$. En la

\footnotetext{
${ }^{49}$ HERRESTAD, Henning, «Philosophical Practice with Suicidal Clients, en Compendium for Paper Presentation of the 7th Internacional Conference on Philosophical Practice, Denmark, 2004, pp. 185-193 (contenida en el texto provisional que nos entregaron en el congreso con la mayoría de las comunicaciones presentadas y en espera de una futurible publicación oficial — que nunca llegó-).

${ }^{50}$ Término alemán de difícil traducción al castellano, por su riqueza y ambigüedad, que implica a su vez los términos «educación» y «cultura», y con connotaciones similares al concepto griego de paideia.

51 SVARE, Helge, «Theory of Bildung and its Relevance for Philosophical Practice», en Compendium for Paper Presentation of the 7th Internacional Conference on Philosophical Practice,
} 
consulta filosófica, podemos aplicar este principio fácilmente: En lugar de preguntar «¿Qué piensas sobre esto?», el filósofo comenzará su investigación preguntado al consultante qué es lo que hizo en una determinada situación, o qué es lo que normalmente hace en ciertos contextos. El propósito de estas preguntas es, en primer lugar, conseguir que nuestro invitado sea más consciente de sus prácticas, en segundo lugar, que las examine de forma crítica y, finalmente, que las modifique. Y a continuación nos expone un caso práctico de una consultante que creía que era demasiado desagradable con sus compañeros de trabajo en la que aplica este modelo kantiano.

Esperamos seguir aprendiendo de las interesantes propuestas del grupo de jóvenes filósofos noruegos y de leer las novedades con las que probablemente nos sorprendan, ya sea con la publicación de un nuevo libro o con la de algún nuevo artículo. Confío en poder volver a verlos en Sevilla en el VIII Congreso Internacional de Práctica Filosófica que tendrá lugar en abril del 2006 (como así sucedió).

\section{La tercera generación: Fastvold y Olsholt}

Por último, no podemos dejar de mencionar aunque solo sea de forma muy somera el trabajo de algunos de los miembros de la tercera generación de filósofos prácticos en Noruega, pues son ellos precisamente quienes está cuestionando alguno de los postulados básicos del modo noruego (y alemán) de concebir y practicar la filosofía práctica $\mathrm{y}$ abriendo nuevos horizontes.

\section{Morten Fastvold, el disidente}

Uno de los filósofos noruegos que se aparta del «enfoque cuidadoso» (caring approach) y políticamente correcto de los noruegos es Morten Fastvold. ${ }^{52}$ Este filósofo práctico, como otros miembros de orientadores

\footnotetext{
Denmark, 2004, p. 208.

${ }^{52}$ Fastvold dispone de una página web (www.fastvold-filopraksis.com) donde se pueden consultar todos los artículos que mencionamos en esta breve semblanza.
} 
filosóficos de la «generación ecléctica» ${ }^{53}$, es partidario de un acercamiento más ecléctico a la disciplina, de un enfoque que sea más «interrogativo» y no tan «conversacional» ${ }^{54}$ como el noruego, de un estilo que sea más filosófico (y que se aleje del paradigma terapéutico que domina, según él, la práctica de la segunda generación ${ }^{55}$ ) y que refleje mejor la influencia socrática. Fastvold ha sido uno de los primeros filósofos noruegos en tomarse en serio el «estilo policíaco» ${ }^{56}$ del francés Óscar Brenifier (uno de los autores por los que nosotros tenemos también una especial devoción), reivindicando la idoneidad y pertinencia de este enfoque. Los análisis que Morten ha desgranado - en un impecable inglés - en una serie de artículos consagrados a la práctica de Brenifier - hasta el momento son seis ${ }^{57}$ — y su contraposición con el enfoque típicamente «blando» de los noruegos son simplemente magistrales ${ }^{58}$.

\footnotetext{
${ }^{53}$ Ocurre algo similar en la filosofía académica (o más bien habría que decir que probablemente este eclecticismo de la generación más joven de filósofos prácticos es el reflejo de lo que también está sucediendo en la filosofía universitaria), donde las nuevas generaciones de filósofos jóvenes apuestan por una conciliación, armonización, fusión o hibridación (como prefieran) de los enfoques (quizás habría que decir más bien, para ser precisos, que los filósofos continentales se están «analitizando» y los analíticos «continentalizando»). Ejemplo de ello es el último libro del filósofo sevillano NAVARRO REYES, Jesús, Cómo hacer filosofía con palabras. A propósito del desencuentro entre Searle y Derrida, FCE, Madrid, 2010.

${ }^{54}$ FASTVOLD, Morten, «Conversation or interrogation: two different approaches to philosophical counseling». Comunicación presentada en el congreso de la UNESCO sobre nuevas prácticas filosóficas celebrado en París, durante los días 15 y 16 de noviembre de 2006. Disponible en línea en http://www.fastvold-filopraksis.com/artikler_pdf/UNESCO\%20final\%20paper\%20MF.pdf (última visita el 30 de abril de 2011).

55 FASTVOLD, Morten, «On Serious Games and the possible Reshaping of a Philosophical Paradigm: Some Reflection on the Sessions of Oscar Brenifier» (abril 2004), disponible en línea en http://www.fastvold-filopraksis.com/artikler_pdf/Serious\%20games.pdf (última visita el 30 de abril de 2011).

${ }^{56}$ FASTVOLD, Morten, «The Policeman Approach to Philosophical Counseling» (octubre 2004), disponible en la red en http:/www.fastvoldfilopraksis.com/artikler_pdf/The\%20Policeman\%20Approach.pdf (última visita el 30 de abril de 2011).

${ }^{57}$ Por ahora, el último de la serie es éste: FASTVOLD, Morten, «Designing Exercises with a Wittgensteinian streak» (octubre 2008), disponible en la red en http://www.fastvoldfilopraksis.com/artikler_pdf/A_Wittgensteinian_streak.pdf (última visita el 1 de mayo del 2011).

${ }^{58}$ Fastvold comenzó con «On Serious Games..." (abril 2004), al que siguió «On Getting Beyond Idle Talk: some Additional Reflections on Oscar Brenifier's Sessions» (mayo 2004), disponible en línea en http://www.fastvold-filopraksis.com/artikler_pdf/On\%20getting\%20beyond\%20idle\%20talk.pdf (última visita el 30 de abril de 2011). Especialmente interesante es el artículo «The Policeman Approach to Philosophical Counseling» (octubre 2004). Continuó con «The Paris Sessions» (agosto 2005, no disponible en su web) y ha seguido con «Wish You Were Here, Where You Don't Want To Be: On The Aristocratic Nature Of Philosophical Consultations, Oscar Style» (agosto 2006),
} 
Una de las características más importantes de los artículos de este incisivo filósofo es que suelen ser el resultado del análisis minucioso de la demostración real y efectiva de las prácticas filosóficas de estos filósofos (Brenifier, Lindseth y von Morstein) y no sólo de las reflexiones teóricas sobre la práctica que estos autores puedan hacer, por lo que nos proporcionan un punto de vista de indudable - e insólito-interés.

En sus últimos artículos, Fastvold continúa diseccionando críticamente con su bisturí irónico e inmisericorde los límites y las insuficiencias de la práctica y los supuestos teóricos de algunos de los más destacados achenbachianos (como Lindseth ${ }^{59}$, von Morstein ${ }^{60}$, e incluso con el propio Achenbach ${ }^{61}$ ) y sigue apostando (contra el parecer de sus mayores de la primera generación) por la necesidad de establecer unas pautas metodológicas en el trabajo de la orientación filosófica que puedan transmitirse a las nuevas generaciones de practicantes y defendiendo la validez de un enfoque ecléctico. ${ }^{62}$ Parece que, según nos cuenta el propio autor ${ }^{63}$, incluso algunos orientadores filosóficos noruegos de la segunda generación están empezando a aceptar las críticas de los filósofos más jóvenes y comienzan también ellos a modificar sus postulados iniciales y a criticar el enfoque achenbachiano ${ }^{64}:$ «No sólo no es inapropiado, sino conveniente e incluso necesario tener acceso a una gran variedad de métodos, además de una habilidad para utilizarlos con buen criterio. Por ello, tanto Svare como yo mismo estamos a favor de

\footnotetext{
disponible en línea en http://www.fastvold-

filopraksis.com/artikler_pdf/Wish\%20you\%20were\%20here.pdf (última visita el 30 de abril de 2011), y siguió con "Conversation or interrogation...» (nov. 2006). El último hasta el momento es FASTVOLD, Morten, «Designing Exercises with a Wittgensteinian streak» (octubre 2008), disponible en la red en filopraksis.com/artikler_pdf/A_Wittgensteinian_streak.pdf (última visita el 30 de abril de 2011).

59 FASTVOLD, Morten, «Beyond method, Anders Lindseth style: The quest to opening up philosophical steps in the consulting room», Philosophical Practice, 1 (3), nov. 2005, pp. 171-183.

${ }^{60}$ FASTVOLD, Morten «Rooting Philosophy in Lived Experience: some Notes on Petra von Morstein's Lecture and Workshops in Oslo, March 2005», disponible on-line en http://www.fastvoldfilopraksis.com/artikler_pdf/MF\%20Essay\%20Petra\%20vM.pdf (última visita el 1 de mayo del 2011)

${ }^{61}$ M FASTVOLD, Morten, «Beyond method...», p. 11 y ss.

${ }^{62}$ FASTVOLD, Morten, «Conversation or interrogation», p. 5

${ }^{63}$ FASTVOLD, Morten, «Conversation or...», p. 3.

${ }^{64}$ SVARE, Helge, «How do we best educate philosophical counselors? Some experiences and reflections from the Norwegian educational program», Philosophical Practice, vol. 2, n. 1, London, 2006, pp. 29-39.
} 
una "caja de herramientas" bien equipada con una serie de estrategias metodológicamente sólidas ${ }^{65}$. Puede que algo esté cambiando en el movimiento de la OrFi.

\section{Øyvind Olsholt, el heterodoxo}

No queremos terminar este artículo sin mencionar por lo menos la labor de otro grupo de filósofos noruegos que están renovando también el campo de la práctica filosófica grupal con niños y jóvenes ${ }^{\mathbf{6 6}}$. Nos referimos a Øyvind Olsholt y Ariane Schjelderup, quienes han desarrollado un modo particular de hacer filosofía con niños que se aparta del enfoque ortodoxo del movimiento de Filosofía para Niños de Lipman (FpN a partir de ahora) y que se asemeja más al enfoque de otras propuestas más heterodoxas y «disidentes», como la Filosofía con Niños de los anglosajones (K. Murris, C. Mc Call, J. Haynes, etc.) o las Nuevas Prácticas Filosóficas francesas (los cafés filosóficos de M. Sautet, los diversos talleres filosóficos de O. Brenifier, o las prácticas y reflexiones de Tozzi, Geneviève, Chazeranas, etc. ${ }^{67}$. En la página web de su asociación (http://buf.no) podemos encontrar un buen número de artículos en inglés donde defienden otra forma de practicar la filosofía con niños (incluyendo trabajos del prácticamente desconocido autor danés Per Jespersen, de Brenifier ${ }^{\mathbf{6}}$, de Fastvold, o entrevistas muy esclarecedoras a Lipman, Sharp, Matthews o Sutcliffe), propuesta que han desarrollado en el libro Filosofía en la escuela ${ }^{\mathbf{6 9}}$ y en varios artículos ${ }^{\mathbf{7 0}}$.

\footnotetext{
${ }^{65}$ FASTVOLD, Morten, "Conversation or...", p. 3.

${ }^{66}$ Fastvold también ha hecho aportaciones en este campo, publicando dos libros sobre el uso del pensamiento crítico en el aula: FASTVOLD, Morten, Ritisk Tenkning. Sokratisk samtaleledelse $i$ skolen, Gyldendal Akademisk, Oslo, 2009, y FASTVOLD, Morten, Supplementsbok Til Kritisk Tenkning. Med eksempler og фvelser, Gyldendal Akademisk, Oslo, 2011.

${ }^{67}$ Para un conocimiento más detallado de las nuevas prácticas filosóficas, remitimos a ARNAIZ, Gabriel, «Evolución de los talleres filosóficos: de la Filosofía para Niños a las Nuevas Prácticas Filosóficas», Childhood \& Philosophy, v. 3, n 5, jan./jun. 2007 (disponible también en línea, en http://www.filoeduc.org/childphilo/n5/GabrielArnaiz.pdf; última visita el 30 de abril de 2011)

${ }^{68}$ De los seis artículos que disponen sobre el francés, destacamos «A quick glance at the Lipman method», donde Brenifier analiza de forma crítica algunos elementos de la práctica tradicional del método Lipman que pudo observar en una de las últimas congresos internacionales sobre $\mathrm{FpN}$ a los que asistió. El artículo está incluido como anexo en su libro La pratique de la philosophie en la école primaire, SEDRAP, 2007 (Está previsto que el próximo setiembre-octubre salga la traducción española: La práctica de la filosofía en la escuela, Diálogo, 2011)

${ }_{69}$ SCHJELDERUP, Ariane; BØRRESEN, Beate; OLSHOLT, Øyvind, Filosofi i skolen, Tane Aschehoug, Oslo, 1999. (En la página de su asociación puede consultarse en inglés el índice y
} 


\section{Conclusión}

Tal como indiqué al inicio de este artículo, mi intención inicial al escribir este texto fue simplemente la de ayudar a ubicar dentro del movimiento internacional de la práctica filosófica el trabajo de la segunda generación de orientadores filosóficos noruegos (Herrestad y Svare), a modo de presentación de la traducción parcial de un libro suyo, contextualizando el trabajo que habían desarrollado e identificando sus fuentes (el trabajo previo de los filósofos prácticos holandeses). Posteriormente, como el artículo no se publicó, decidí ampliar su radio de acción y considerar también el trabajo de la generación anterior (Lindseth), fuertemente influida por el trabajo de Achenbach, que rechaza toda asimilación de la OrFi a cualquier tipo de terapia y cuyo trabajo se basa en la tradición de la filosofía (universitaria) continental, y el la tercera generación (Fastvold), que me parecía muy interesante. Esto me hizo reflexionar de manera más sistemática sobre la dialéctica generacional en el movimiento de la práctica filosófica (y su similitud o equivalencia con las corrientes filosóficas universitarias).

De esta forma, lo que pretendía meramente ser una primera aproximación al tipo de orientación filosófica que se practica y predica en noruega, se convirtió inesperadamente en una atípica historia del movimiento y en un análisis de las corrientes subterráneas que luchan por adquirir hegemonía, y también en un pequeño esbozo metametodológico, que aportaba algunos ingredientes quizás interesantes para una futura epistemología de la práctica filosófica. ${ }^{71}$ Descubrí, pues, que la

\footnotetext{
algunos fragmentos del libro.)

${ }_{70}$ OLSHOT, Øyvind y SCHJELDERUP, Ariane, «Philosophy for Children: A Norwegian Approach», Philosophy in Society, Unipub, Oslo, 2004, pp. 123-133 (disponible también en 1, a red, en http://www.buf.no/en/read/txt/?page=pis-01-en; última visita el 30 de abril de 2010). En la web que comentamos puede consultarse otros materiales que estos autores han elaborado, así como una entrevista muy jugosa a Olshot.

${ }^{71}$ Entiendo por meta-metodología la reflexión sobre las diversas metodologías (siendo la metodología la reflexión sobre un método o práctica), que correspondería a la epistemología en un sentido amplio. En la nota 78 sugiero una continuidad entre la práctica (filosófica en este caso) y la teoría y defino brevemente los términos: la serie sería meta-práctica (metodología), metametodología (epistemología) y meta-metametodología (metafilosofía) y por último metametafilosofía (Véase al respecto FERRATER MORA, José, «Metametafilosofía», Modos de hacer filosofía, Crítica, Barcelona, 1985, pp. 26-33). (En un futuro próximo me gustaría escribir - ya estoy otra vez «orteguizando»- un artículo sobre la distinción entre la teoría y la práctica, y sus relaciones
} 
primera generación de orientadores (Achenbach y sus seguidores) había empezado a practicar este enfoque en los ochenta ${ }^{72}$ era de estirpe continental y rechazaba todo contacto y comunicación con la psicología y los terapeutas (y que en sus modos aparentemente blandos reflejaban pero eso es otra historia - una rigidez y un integrismo ${ }^{73}$ típico de conversos). La segunda generación (representada por Marinoff y los angloamericanos) había descubierto el fenómeno en los noventa, tenía una filiación analítica y estaba dispuesta a dialogar —un diálogo que no está exento de crítica y conflicto - con las terapias - al menos con algunas de ellas: cognitiva (Ellis), humanista (Rogers), existencial (Frankl, May), sistémica (Watlazwick), etc.-, a reconocer el carácter terapéutico de la OrFi y a ampliar su ámbito de aplicación a otras prácticas filosóficas que habían surgido en aquel momento (cafés y talleres filosóficos) o que, aunque se hubiesen creado con anterioridad, se descubría ahora su raíz común (Filosofía para niños, diálogos socráticos), el «giro práctico» en el que todas estaban inmersas. También ampliaron el radio de acción geográficamente, pues fueron los responsables de la globalización del fenómeno, y de que el movimiento adquiriese una proyección internacional (también gracias al inglés, la nueva lengua franca) y una vertiginosa institucionalización (revistas, congresos y asociaciones con proyección internacional). Esta incomprensión y antagonismo entre las dos concepciones de la OrFi (dependientes sin duda de las dos tradiciones antagónicas de las que parten: la analítica y la

(y claro, para ello, habría que esclarecer también las conflictivas y necesarias relaciones entre la «filosofía universitaria» y la «filosofía mundana» - algo he apuntado en la nota 25-), para esclarecer muchas confusiones.)

${ }^{72}$ Aunque otros filósofos (Michael Russell, o Cencillo, por ejemplo) alegan — siempre a posteriorihaber estado ejerciendo en la década de los setenta (década cero: 1970-1980) eso mismo, pero «travestido» de terapia (es decir, bajo la apariencia de "terapia" o psicología estaban en realidad «vendiendo» filosofía). Hay que decir que en la mayoría de los casos nos encontramos con filósofos que también poseen una formación terapéutica. Más bien creemos que esta fase previa, inicial, lo que se está ofreciendo sería más bien algún tipo de «terapia filosófica» y no propiamente dicho orientación filosófica.

${ }^{73} \mathrm{Si}$ una anécdota puede servir de prueba (si no, al menos de indicio), puedo citar en mi caso la agridulce experiencia con Achenbach y Lindesth en una entrevista que le hice en la conferencia de Dinamarca (y donde tuve que padecer sus reticencias, su suspicacia, su rigidez y la cortedad de miras de ambos (y en menor medida, cierta distancia de Svare y de Hansen), frente a la facilidad de trato, la cercanía y la apertura mental de las conversaciones con Marinoff, Russell, , Jongsma, Bolten, Prawda, etc (y Fastvold, a pesar de ser noruego). El análisis sobre el integrismo puritano de los achenbachianos, lo dejo para otro lugar y momento. 
continental) ha provocado notables fricciones (por lo visto en el segundo congreso que se celebró en Alemania, según cuentan las crónicas), que son similares o equivalentes a las polémicas que cada cierto tiempo afloran en la filosofía universitaria (Carnap vs. Heidegger, Derrida vs. Searle, Sokal y Bouveresse vs. Posmodernos, etc.). La tercera generación está intentando superar dialécticamente estos dos momentos (tesis: primera; antítesis, segunda), destapando los presupuestos implícitos que dan por sentado y proponiendo un enfoque «ecléctico» (en consonancia también con los intentos en sus respectivas tradiciones de superar esta dicotomía entre analíticos y continentales) que las supere, y que incorpore lo mejor de ambas tradiciones.

En el caso específico que nos ocupa, no tanto el movimiento internacional en su conjunto (las fuerzas de los diferentes países - $\mathrm{O}$ imperios $^{74}$ - por conquistar un espacio, en este caso intelectual ${ }^{75}$ sino las fuerzas o corrientes dentro de una región (los países nórdicos, y en particular Noruega, el más activo en este campo hasta el momento), podemos decir que la primera generación era achenbachiana, al formar parte de los fundadores iniciales (Lindesth); la segunda, compuesta por Herrestad y Svare, ha incorporado (influido por el enfoque pragmático de los holandeses, afín al estilo americano) ciertos elementos propios del enfoque analítico (un cierto pragmatismo, una consideración más amplia

\footnotetext{
${ }^{74}$ Marinoff ha sido el primero en esbozar un análisis político de la PF desde una perspectiva realista o «neohobbesiana», y sus agudas observaciones no tienen desperdicio: «También ha habido tensiones políticas, naturalmente, que se experimentan como débiles ecos de fuerzas políticas e históricas muco más fuertes. Por ejemplo, en 1998, la Sociedad Alemana para la Práctica Filosófica cambió su nombre a la "Sociedad Internacional para la Práctica Filosófica". Esto no sucedió sin la oposición de algunos de sus propios miembros alemanes, quienes entendieron (correctamente) que esto podía ser percibido como una recrudescencia de la ambición imperialística. Además, aunque otras organizaciones nacionales poseen también miembros de otras nacionalidades, ninguna se ha arrogado exclusivamente esa prerrogativa. Como respuesta, fundé con Ernesto Spinelli, entonces presidente de la Sociedad para el Análisis Existencial, la Alianza Angloamericana para la Práctica Filosófica, y posteriormente vimos un nuevo fenómeno en el horizonte internacional; o más bien, el eco de un viejo fenómeno: esto es, la competición entre la influencia europea y americana en el ámbito de la práctica filosófica. Igual que en política y en economía, podemos reencontrar cierta rivalidad entre el Viejo Mundo y el Nuevo Mundo, esta vez manifestándose en la arena noética de la práctica filosófica», en MARINOFF, Lou, Philosophical Practice, Academic Press, New York, 2001, pp. 352-353.

${ }^{75} \mathrm{La}$ escuela sociológica que se inspira en Bourdieu (Pinto, Moreno Pestaña, etc.) ha analizado con detenimiento la dialéctica de fuerzas existentes en los diferentes campos. Para las referencias bibliográficas, véase la nota 78 .
} 
de la PF, incluyendo también, por ejemplo, el uso del DS en la tradición de Nelson), pero conservando intactos los supuestos básicos (los principios) que conforman el «enfoque blando» de la primera generación (y a nuestro juicio, poco o nada filosófico). La tercera generación, personificada por el trabajo de poda - me atrevería a decir incluso de demolición - que ha emprendido Fastvold al poner al descubierto las limitaciones y carencias de este enfoque y la poca o nula filosoficidad del mismo, ha puesto sobre el tapete la esencia del enfoque filosófico ${ }^{76}$ (frente el enfoque terapéutico), entroncando así con uno de los postulados básicos de la primera generación (la demarcación con la psicoterapia) ${ }^{77}, \mathrm{y}$ reduciendo el diálogo filosófico a sus características fundamentales. El silogismo de Fastvold (muy influido por la práctica de Brenifier) podría muy bien ser éste: si se propicia una aproximación amigable del diálogo filosófico, atenuamos el elemento conflictivo, con lo que le «afeitamos los cuernos» al diálogo socrático y reducimos el grado de filosoficidad de éste (tesis con la que estoy de acuerdo) ${ }^{78}$. En suma, sin aspereza no hay filosofía; si el remedio no escuece, no hay cura. Fastvold defiende un

\footnotetext{
76 Por ejemplo, Pollastri, ha intentado superar el «radicalismo» inicial de Achenbach (que consideraba la orientación filosófica como contradistinta de la psicoterapia —entendida casi exclusivamente como psicoanálisis - y opuesta a la filosofía académica), corrigiendo algunas limitaciones de su enfoque y defendiendo una visión más abierta y dialogante (con la filosofía universitaria, por un lado, y por otro, con las psicoterapias en un sentido más amplio y plural) del «enfoque filosófico» característico de la OrFI. Véase POLLASTRI, Neri, «Osservazioni per una definizione della consulenza filosofica», Kykéion, n. ${ }^{\circ}$ 8, Firenze, 2002 [Existe traducción española: «Aportaciones para una definición positiva de la orientación filosófica», El Búho, n ${ }^{\circ}$ 9, 20011, disponible en línea en http://elbuho.aafi.es/ (última vista el 29 de mayo 2011)]

77 Algo parecido a la demarcación radical entre metafísica y ciencia de Popper, o de Filosofía y pseudofilosofía de los positivistas lógicos.

${ }^{78}$ Aunque ya estoy oyendo la previsible respuesta de Marinoff, cuando responde a las objeciones de los críticos a la PF de que hay muy poca filosofía en este tipo de diálogos filosóficos (así lo hace en Philosohpical Practice, por ejemplo), de que esta filosofía está muy diluida o «aguachirlada», replica con un argumento analógico: aunque tu cubata tenga poca cantidad de alcohol (no olvidemos que en los países nórdicos y de influencia germánica — sin duda por su origen protestante - sólo te sirven 10 centímetros cúbicos de alcohol en cada combinado, y eso lo sabe Marinoff), sigue teniendo la capacidad de embriaguar, el alcohol allí existente sigue siendo efectivo y mantiene todas sus propiedades, aunque si bien es cierto, que necesitarás beber un mayor número de ellos para emborracharte. Pero lo fundamental es que la capacidad de embriagar permanece, aunque ésta esté disminuida. Para empantanar un poco más el alambicado «sistema» de notas que componen este ¿artículo?, anunciaré - ¿otra vez más? - que me gustaría tratar sobre este punto en breve: sobre la necesaria «aspereza» del método socrático. Y esta nota, así como las referentes a la metafilosofía y a la sociología de la filosofía, reflejan mejor mis preocupaciones actuales (aunque si dejo pasar mucho tiempo, claro está, «caducarán» como las anteriores).
} 
«enfoque duro» (a juicio de los blandos, claro está), «áspero» (recordemos la aspereza del método cínico, por ejemplo), «policial» (ejerciendo el papel de «poli malo», claro está), que permita que se pueda filosofar.

De este modo, al investigar sobre la práctica (al hacer metapráctica $^{79}$ ), al buscar describir los rasgos fundamentales de la práctica filosófica de los filósofos nórdicos me encontré haciendo teoría, y cada vez más teórica, (de la meta-metodología —o epistemología de las prácticas filosóficas - a la meta-filosofía, al análisis de las concepciones filosóficas que subyacen a las diversas prácticas). Y sin buscarlo en un principio, descubrí ciertas conclusiones que me ayudaban a entender la historia reciente de la filosofía universitaria (de la práctica de la teoría), a comprender la dinámica de tipo dialéctico que subyace en la evolución histórica de las tradiciones (analítica y continental), familias y corrientes, acercándome a los análisis que viene desarrollando, por ejemplo, la Sociología de la Filosofía ${ }^{80}$. En consecuencia, fui pasando sin darme cuenta de la teoría de la práctica a la práctica de la teoría.

Después de todo esto, tengo la agridulce sensación de haber hecho algo parecido a lo que con demasiada frecuencia solía hacer Ortega y Gasset: con el pretexto de tratar un tema secundario o aparentemente banal (ya fuese un marco de un cuadro, las bicicletas en Holanda, el

\footnotetext{
${ }^{79}$ La meta-práctica sería la reflexión sobre el método, sobre una determinada práctica (en el caso en el que nos ocupa, sobre una determinada práctica filosófica, por ejemplo, la orientación filosófica), es decir, la metodología. La meta-metodología (la reflexión sobre las diversas metodologías) sería, pues, epistemología (por ejemplo, la investigación sobre los diferentes enfoques que componen el movimiento de la orientación filosófica, o sobre las características comunes y diferentes entre los diversos movimientos que integran la Práctica Filosófica en un sentido amplio). Y la «meta-metametodología» (la reflexión sobre los fundamentos y principios que sustentan estas diversas metodologías) sería meta-filosofía. La meta-práctica es por lo tanto teoría (aunque con minúsculas).

${ }^{80}$ Desde hace un tiempo me viene interesando mucho el trabajo de esta reciente disciplina (a medio camino entre la sociología y la filosofía), especialmente de la escuela que parte de Bourdieu. Me gustaría mucho en un futuro cercano escribir un artículo introduciendo el trabajo de alguno de estos autores. Por el momento, baste esta mínima selección bibliográfica: COLLINS, Randall, Sociologías de la filosofía. Una teoría global del cambio intelectual, Hacer, Barcelona, 2005; BOURDIEU, Pierre, Homo academicus, Anagrama, Barcelona, 1999; PINTO, Louis, Les philosophes entre le lycée et l'avant-garde. Les metamorphoses de la philosophie dans la France d'aujourd'hui, L'Harmattan, Paris, 2000; PINTO, Louis, La vocation et le métier de philosophe. Pour une sociologie de la philosophie dans la France contemporaine, Seuil, Paris, 2007; MORENO PESTAÑA, José Luis y VÁZQUEZ GARCÍA, Francisco, Pierre Bourdieu y la filosofía, Montesinos, Barcelona, 2006; VÁZQUEZ GARCÍA, Francisco, La filosofía española. Herederos y pretendientes. Una lectura sociológica, Abada, Madrid, 2010.
} 
último libro de Toynbee, la filosofía de Leibniz, o lo que se terciase) aprovechaba para colar «de matute» toda una serie de cuestiones filosóficas de cierta relevancia mucho más importantes y trascendentales que el tema en cuestión que estaba abordando (aunque quizás no tan atractivas), lo que hacía que fuese difícil saber con seguridad cuáles eran los problemas filosóficos que se iban a desarrollar en ese ensayo. Al final, lo más interesante del susodicho artículo de las bicicletas, por citar sólo uno de los ejemplos más paradigmáticos, venía cuando nuestro filósofo adelantaba un análisis muy pertinente sobre el surgimiento del nazismo en Alemania (¡quien lo hubiera imaginado!). Así, no era infrecuente que las mejores perlas de Ortega estén dispersas en los artículos más insospechados y sobre los temas más peregrinos. El problema es que, claro está, yo no soy Ortega, y mis potenciales lectores, que no tienen la devoción de los lectores del filósofo madrileño (quienes leerían casi cualquier texto del autor, sabiendo que en cualquier sitio puede ofrecerles esa intuición esclarecedora que ilumine no sólo el problema aparentemente trivial que está tratando, sino otros de mayor calado), por lo que van a ser muy pocas personas (menos de las podrían si hubiese desgajado la parte más sustanciosa del artículo y lo hubiese convertido en un artículo independiente) las que se beneficien de los análisis más interesantes del mismo. Además, para diferenciar aún más el símil, Ortega solía elegir una cuestión por la que el lector no especializado estuviese previamente interesado (ahí residía su maestría y también su mayor limitación), y el tema que yo he elegido no tiene demasiado atractivo para un lector interesado en la práctica filosófica (seamos sinceros, ¿a cuántas personas les puede interesar lo que están haciendo los filósofos noruegos en el campo de la PF?).

Me consuela pensar que, como dice Ferrater Mora, la filosofía puede expresarse de múltiples formas (tratado, diálogo, ensayo...) y no sólo de una, lo que importa, eso sí, es que sea sistemática ${ }^{81}$. En este artículo he intentado comprender una realidad (la PF en Noruega), y para ello he tenido que investigar a su vez que era la Práctica Filosófica ${ }^{82}$, y para

\footnotetext{
${ }^{81}$ FERRATER MORA, José, «Filosofía y literatura», Modos de hacer filosofía, Crítica, Barcelona, 1985, pp. 120-121.

${ }^{82}$ Así lo hice en mi tesina (ARNAIZ, Gabriel, El giro práctico en filosofía. Análisis y fundamentación de las prácticas filosóficas. Universidad de Sevilla, 2007, inédito), que me ha
} 
comprenderla he tenido a su vez que investigar en qué consistía la filosofía (tanto la académica como la mundana, y las relaciones entre sí - o como diría Kant, el concepto escolástico de filosofía (der Schulbegriff der Philosophie) y el concepto cósmico, universal o cosmopolita de la filosofía (der Weltbegriff der Philosophie) ${ }^{83}$-, sus ramas y campos (filosofía teórica, filosofía práctica, filosofía aplicada, etc.), la distinción entre teoría y práctica, en qué consistía un diálogo filosófico (donde estaba la filosoficidad de éste), y otras cuestiones anejas

llevado a interesarme más por la metafilosofía y la metametafilosofía. Para una primera toma de contacto, véase FERRATER MORA, «Metafilosofía», «Metaciencia» y «Metaética, en Diccionario de Filosofía I-M, Ariel, Barcelona, 1994, pp. 2375-2378. Dice allí que «la metafilosofía es un análisis de la "actividad filosófica". [...] "Metafilosofía [según Morritz Lazerowitz, al que Ferrater cita] es la investigación de la naturaleza de la filosofía, con el propósito capital de alcanzar una satisfacción satisfactoria de la ausencia de alegatos y argumentos filosóficos no impugnados. [...] no puede ya ponerse en duda, para filósofos que traten su disciplina seriamente, que es menester tener una mejor comprensión de la filosofía, de lo que es y de cómo funciona". [...] Se puede asimismo considerar que la metafilosofía es una parte integrante, y no sólo propedéutica, de la filosofía, es decir, considerar que la filosofía comporta un examen de sí misma y, por tanto, lo que se ha llamado a veces una "dimensión filosófica". En este sentido, la estructura de los estudios metafilosóficos no coincide con la de los estudios de metaciencia y ni siquiera con los estudios de metaética. [...] Por otro lado, [...] [la metafilosofía] consiste en gran parte en un examen de ciertas nociones que se emplean en filosofía, aunque las más de las veces sólo implícitamente.» (pp. 2377-8).

${ }^{83}$ Quizás el análisis más claro de las dos concepciones kantianas de la filosofía, la relación entre ellas y su vinculación con la filosofía que se hace en el presente se deba a CONANT, James, «Introduction», en PUTNAM, Hillay, Realism with a Human Face, Harvard University Press, Cambridge (Mass.), 1990, pp. XXV-XXXII: «Al distinguir entre la Schulbegriff y la Weltbegriff, Kant se refiere a ellas como dos conceptos de la filosofía. Esto sugiere que, para Kant, no es una cuestión de delinear dos tipos diferentes de filosofía, sino más bien de distinguir dos polos diferentes de una misma actividad, lo que implica no sólo que cada uno de estos polos tiene legítimo derecho al título de «filosofía», sino que la empresa filosófica en sí misma sólo puede dar todos sus frutos cuando se la ejerce bajo el aspecto de cada uno de los dos. [...] Kant nos dice que el concepto cósmico o universal (Weltbegriff) de la filosofía se preocupa de "la relación de todo el conocimiento con los fines esenciales de la razón humana". Después añade: "El concepto universal quiere significar un concepto relacionado con aquello que debe interesarle a todo el mundo". [...] El investigador filosófico que no tenga en cuenta (o rechace) las aspiraciones de la filosofía cósmica o universal, según Kant, traiciona (o renuncia a) la responsabilidad principal de la vocación del filósofo: la responsabilidad de dirigirse a las necesidades intelectuales universales de sus compañeros seres reflexivos. Si la práctica de la filosofía se realiza exclusivamente no sólo por especialistas, sino que, además, se dirige exclusivamente $a$ las necesidades e intereses de los especialistas, entonces no debería llamarse propiamente «filosofía»: "También está el concepto cósmico o universal de filosofía (Weltbegriff), que siempre ha constituido el fundamento real al que se le ha dado el título de [filosofía]". [...] Uno podría resumir el carácter de la naturaleza dual aquí descrita parafraseando el famoso aforismo kantiano que habla de la relación entre los conceptos del entendimiento y las intuiciones de la sensibilidad: el Weltbegriff de la filosofía sin el Schulbegriff está vacío, y el Schulbegriff sin el Weltbegriff está ciego. 
(el estilo propio del filosofar, la Ilustración, etc.). Todo ello me ha llevado a sugerir los resultados de estas investigaciones en las que me baso para sostener mis afirmaciones a lo largo del texto (y quizás más veces de las necesarias a indicar sucintamente lo que quería decir en numerosas notas a pie de página; en este punto he sido anti-orteguiano, pues he intentado - siempre que me ha sido posible - aportar pruebas de lo que afirmo, aunque soy consciente de que me he dejado muchas cosas en el tintero, de ahí las continuas referencias a artículos futuros).

Es decir, que para escribir el artículo sobre la PF en Noruega he necesitado investigar tanto como para escribir otra serie de artículos (los que se anuncian en las notas, que he abordado con mayor extensión en mi tesina, como digo), de la misma extensión que el cuerpo central de éste, donde aclararía los puntos en los que me baso para defender las cuestiones que aquí trato, pero como soy más socrático que aristotélico, he intentado paliar la «mutilación» de las pruebas que sustentaban el discurso principal con una serie de glosas que serían el esqueleto de esos futuros artículos que seguramente no escribiré.

Así que disfruten con esta resurrección del género filosófico de la «glosa» (del que soy asiduo practicante, en este caso «glosador» de mí mismo, lo que si cabe es todavía más enfermizo) en que consiste este artículo bifronte y algo abigarrado ${ }^{84}$.

\section{Bibliografía}

ACHENBACH, Gerd. «Breve respuesta a la pregunta: “¿Qué es la orientación filosófica"», disponible en la red en http://www.asepraf.org/practica\%20filosofica\%20Achenbach.pdf (última visita el 1 de mayo del 2011) [traducción y notas de G. Arnaiz].

\footnotetext{
${ }^{84}$ Y que me perdonen Popper y Feyerabend (aún recuerdo con delectación algunas de sus extensas notas, especialmente la nota 13 de Contra el método, con más de ¡7 páginas de extensión!), maestros contemporáneos en el arte de la glosa, por la brevedad de las mías, especialmente éste último, al que sigo en su rechazo del estilo impersonal de los escritos filosóficos y «científicos» contemporáneos y su reivindicación de un estilo más personal y subjetivo, que incorpore el yo del investigador, como hacían en su momento los pioneros de la revolución científica. Pues como pioneros de la PF, nos hemos permitido estos «desmanes».).
} 
ARNAIZ, Gabriel, «¿Qué es la Filosofía Práctica?», A parte rei, n ${ }^{\circ}$ 3, 2007, disponible en línea en http://serbal.pntic.mec.es/AParteRei/arnaiz53.pdf (última visita el 9 de mayo del 2011).

— «El giro práctico de la filosofía», Diálogo filosófico, Madrid, $\mathrm{n}^{\circ}$ 68, 2007. Disponible también en línea en http://www.ciudadredonda.org/admin/upload/files/1cr_t_adjuntos_268.pd f; última visita el 30 de abril de 2010).

FASTVOLD, Morten, «On Serious Games and the possible Reshaping of a Philosophical Paradigm: Some Reflection on the Sessions of Oscar Brenifier» (abril 2004), disponible en línea en http://www.fastvoldfilopraksis.com/artikler_pdf/Serious\%20games.pdf (última visita el 1 de mayo del 2011).

- «On Getting Beyond Idle Talk: some Additional Reflections on Oscar Brenifier's Sessions» (mayo 2004), disponible en línea en http://www.fastvold-

filopraksis.com/artikler_pdf/On\%20getting\%20beyond\%20idle\%20talk.p df (última visita el 1 de mayo del 2011).

- «The Policeman Approach to Philosophical Counseling» (octubre 2004), disponible en la red en http://www.fastvoldfilopraksis.com/artikler_pdf/The\%20Policeman\%20Approach.pdf (última visita el 1 de mayo del 2011).

- «Beyond method, Anders Lindseth style: The quest to opening up philosophical steps in the consulting room», Philosophical Practice, 1 (3), London, 2005, pp. 171-183. Disponible también en línea, en http://www.fastvold-filopraksis.com/artikler_pdf/Lindseth\%20e-print.pdf (última visita el 1 de mayo del 2011).

- «Rooting Philosophy in Lived Experience: some Notes on Petra von Morstein's Lecture and Workshops in Oslo, March 2005», disponible on-line en http://www.fastvoldfilopraksis.com/artikler_pdf/MF\%20Essay\%20Petra\%20vM.pdf (última visita el 1 de mayo del 2011).

- «Wish You Were Here, Where You Don't Want To Be: On The Aristocratic Nature Of Philosophical Consultations, Oscar Style» (agosto 2006), disponible en línea en http://www.fastvold- 
filopraksis.com/artikler_pdf/Wish\%20you\%20were\%20here.pdf (última visita el 1 de mayo del 2011).

- «Conversation or interrogation: two different approaches to philosophical counseling». Comunicación presentada en el congreso de la UNESCO sobre nuevas prácticas filosóficas celebrado en París, durante los días 15 y 16 de noviembre de 2006. Disponible en línea en http://www.fastvold-

filopraksis.com/artikler_pdf/UNESCO\%20final\%20paper\%20MF.pdf (última visita el 1 de mayo del 2011).

- «Designing Exercises with a Wittgensteinian streak» (octubre 2008), disponible en la red en http://www.fastvoldfilopraksis.com/artikler_pdf/A_Wittgensteinian_streak.pdf (última visita el 1 de mayo del 2011).

HANSEN, Finn T., «The Use of Philosophical Practice in Lifelong and Self-Directed Learning», en HERRESTAD, Heninng; HOLT, Anders y SVARE, Helge (eds.), Philosophy in Society, Unipub, Oslo, 2004, p. 6173.

HERRESTAD, Henning, «The Oslo Model: a successful Two Year Training Programme in Philosophical Counselling», en CURNOW, Trevor (ed.), Thinking through Dialogue, Practical Philosophy Press, Oxford, 2001, pp. 11-15.

- «Short Socratic Dialogue», en HERRESTAD, Heninng; HOLT, Anders y SVARE, Helge (eds.), Philosophy in Society. Papers presented to the Sixth Internacional Conference on Philosophy in Practice, Unipub, Oslo, 2004, pp. 91-102.

HERRESTAD, Henning, SVARE, Helge, «En la consulta del filósofo», Revista ETOR, ${ }^{\circ}$ 4, Sevilla, 2005, pp. 63-68.

LINDSETH, Anders, «What The Other Says And What (S)He Talks About: Some Foundations of a Theory of Philosophical Practice», en CURNOW, Trevor (ed.), Thinking through Dialogue, Oxford, Practical Philosophy Press, 2001, p. 135.

- «Philosophical Practice. What is at stake?», en HERRESTAD, Heninng; HOLT, Anders y SVARE, Helge (eds.), Philosophy in Society. Papers presented to the Sixth Internacional Conference on Philosophy in Practice, Unipub, Oslo, 2004, p. 18. 
- Zur Sache der Philosophischen Praxis. Philosophieren in Gesprächen mit ratsuchenden Menschen, Verlag Kart Aber, Loegstrup, 2005.

OLSHOT, Øyvind y SCHJELDERUP, Ariane, «Philosophy for Children: A Norwegian Approach», Philosophy in Society, Unipub, Oslo, 2004, pp. 123-133. Disponible también en la red, en http://www.buf.no/en/read/txt/?page=pis-01-en (última visita el 30 de abril de 2010).

SVARE, Helge, «The Philosophy of Dialogue», en HERRESTAD, Heninng; HOLT, Anders y SVARE, Helge (eds.), Philosophy in Society, Unipub, Oslo, 2004, pp. 243-250.

- «How do we best educate philosophical counselors? Some experiences and reflections from the Norwegian educational program», Philosophical Practice, vol. 2, n. 1, London, 2006, pp. 29-39. 
